\title{
Creep Damage Evaluation using Uniaxial Miniature Specimens for Multiaxially Damaged Components
}

\author{
Rui Kosaka ${ }^{1}$, Fumio Ogawa ${ }^{2}$, Takamoto Itoh $^{2}$, and Masao Sakane ${ }^{2,2}$ \\ ${ }^{1}$ Department of Mechanical Engineering, Graduate School of Science and Engineering, Ritsumeikan \\ University, Japan \\ ${ }^{2}$ Department of Mechanical Engineering, College of Science and Engineering, Ritsumeikan \\ University, Japan
}

\begin{abstract}
This study discusses a method of evaluating multiaxial creep damage for high temperature components subjected to multiaxial creep damage utilizing a miniature creep testing. A new model of the damage evaluation is proposed based on a linear creep damage accumulation and von Mises equivalent stress being a measure of multiaxial creep damage. The model clearly indicates that conventional creep damage evaluation methods utilizing a unidirectional miniature creep testing give an unconservative estimate in some cases for multiaxially creep damaged components. To verify the appropriateness of the proposed model, multiaxial creep tests were performed using cruciform specimens of a Mod.9Cr-1Mo steel. Miniature specimens in two directions were machined from a pre-damaged cruciform specimen and the uniaxial creep rupture lifetimes of the miniature specimens demonstrate the validity of the proposed model.
\end{abstract}

\section{Introduction}

Fossil power plants are going to be operated at higher temperatures under higher pressures to achieve better energy efficiency [1]. Mod.9Cr-1Mo steels have been widely used as a structural material in fossil plants due to their excellent high temperature performance. Boiler tubes are a typical part of fossil plants where biaxial stresses arise by internal steam pressure [2]. Creep damage evaluation is the key technology to a safe and efficient operation of the fossil plant, so that non-destructive and destructive creep damage evaluations methods have been applied to such boiler tubes. Most reliable creep damage evaluation method is to machine a miniature creep specimen from the damaged part and to obtain residual creep rupture lifetime of the miniature specimen. We can calculate damage of the tube underwent during operation through the residual rupture lifetime of the miniature specimen. This creep damage evaluation method has been widely applied because the method is believed to carry a high reliability [3]. The method is, in a sense, the combination method of the advantageous parts of a non-destructive and destructive damage evaluation testing. 
The creep damage evaluation method utilizing a miniature specimen, however, arises a question whether we can evaluate creep damage through a residual lifetime of the uniaxial miniature specimen for multiaxially creep damaged part. As far as the authors know, no theoretical and experimental studies have been reported about this question whereas this research topic is essential to the reliability of a creep damage evaluation in practice.

The objective of this paper is to discuss a creep damage evaluation method using a miniature creep testing for multiaxially damaged components. A new creep damage model is presented in this paper. The model reveals a limitation of conventional creep damage evaluation methods using a miniature specimen and this study proposes an improved method to overcome the limitation using plural miniature creep specimens in different directions taken from multiaxial damaged components. Biaxial creep and miniature uniaxial creep tests are also performed to confirm the validity of the proposed model and method using a Mod.9Cr-1Mo steel.

\section{Multiaxial creep damage model}

\subsection{Multiaxial creep damage model}

The principal stress ration $(\lambda)$ is defined in this paper as the ratio of the y-directional principal stress $\left(\sigma_{\mathrm{y}}\right)$ to the $\mathrm{x}$-directional principal stress $\left(\sigma_{\mathrm{x}}\right)$ as $\lambda=\sigma_{\mathrm{y}} / \sigma_{\mathrm{x}}$. The principal stress ratio of $\lambda=0.0$ corresponds with a uniaxial tensile creep test that of $\lambda=0.5$ is a biaxial tensile creep test where $\sigma_{\mathrm{y}}$ has a half magnitude of $\sigma_{\mathrm{x}}$. The principal stress ratio of $\lambda=1.0$ is an equi-biaxial tensile creep test where $\sigma_{\mathrm{y}}$ has the same magnitude as $\sigma_{\mathrm{x}}$, Fig. 1 .

\begin{tabular}{|c|c|c|c|}
\hline$\lambda$ & 0.0 & 0.5 & 1.0 \\
\hline State & Uniaxial & Biaxial & Equi-biaxial \\
\hline & & $\sigma_{\mathrm{y}}$ & $\sigma_{\mathrm{y}}$ \\
Multiaxial & $\sigma_{\mathrm{x}} \leftarrow \square \rightarrow \sigma_{\mathrm{x}}$ & $\sigma_{\mathrm{x}} \leftarrow \square \rightarrow \sigma_{\mathrm{x}}$ & $\sigma_{\mathrm{x}} \leftarrow \square \rightarrow \sigma_{\mathrm{x}}$ \\
stress state & & $\sigma_{\mathrm{y}}$ & $\downarrow$ \\
& & $\sigma_{\mathrm{y}}$ \\
\hline
\end{tabular}

Fig. 1. Definition of the principal stress ratio.

Von Mises equivalent stress $\left(\sigma_{\text {eq }}\right)$ is used to express creep damage here under multiaxial stress states expressed in Eq. (1).

$$
\sigma_{e q}=\frac{\sqrt{2}}{2}\left\{\left(\sigma_{x}-\sigma_{y}\right)^{2}+\left(\sigma_{y}-\sigma_{z}\right)^{2}+\left(\sigma_{z}-\sigma_{x}\right)^{2}\right\}^{\frac{1}{2}}
$$

In the equation, $\sigma_{x}, \sigma_{y}$ and $\sigma_{z}$ are the $x$-directional, $y$-directional and z-directional principal stresses, respectively. The relationship between von Mises stress and the three principal stresses is expressed by the following equation for the case of the equi-biaxial stress state $(\lambda$ $=1.0)$ shown in Fig. 1 setting $\sigma_{\mathrm{x}}=\sigma_{\mathrm{y}}=\sigma$ and assuming plane stress condition $\left(\sigma_{\mathrm{z}}=0\right)$.

$$
\sigma_{\mathrm{x}}=\sigma_{\mathrm{y}}=\sigma=\sigma_{\mathrm{eq}}
$$


Von Mises equivalent strain $\left(\varepsilon_{\text {eq }}\right)$ can be expressed with the three principal creep strains $\left(\varepsilon_{\mathrm{x}}\right.$, $\left.\varepsilon_{\mathrm{y}}, \varepsilon_{\mathrm{z}}\right)$ as,

$$
\varepsilon_{e q}=\frac{\sqrt{3}}{2}\left\{\left(\varepsilon_{x}-\varepsilon_{y}\right)^{2}+\left(\varepsilon_{y}-\varepsilon_{z}\right)^{2}+\left(\varepsilon_{z}-\varepsilon_{x}\right)^{2}\right\}^{\frac{1}{2}}
$$

From the incompressibility of creep deformation, the following equation holds.

$$
\varepsilon_{\mathrm{x}}+\varepsilon_{\mathrm{y}}+\varepsilon_{\mathrm{z}}=0
$$

The $i$-diretional principal creep strain rate $\left(\dot{\varepsilon}_{i}\right)$ is derived from the creep potential theory [4] as,

$$
\begin{gathered}
\dot{\varepsilon}_{i}=\frac{3}{2} \frac{\dot{\varepsilon}_{e q}}{\sigma_{e q}} S_{i} \\
S_{i}=\sigma_{i}-\frac{1}{3}\left(\sigma_{x}+\sigma_{y}+\sigma_{z}\right) .
\end{gathered}
$$

In above equations, $S_{i}$ is the principal deviatoric stress shown in Eq. (6) and $i$ stands for $x, y$ or $z$. Norton's power creep law shown in Eq. (7) is used to relate between von Mises strain and von Mises stress rate under multiaxial stress states.

$$
\dot{\varepsilon}_{e q}=\alpha \sigma_{e q}^{\beta}
$$

Rupture lifetimes are estimated based on the Monkman-Grant equation [5] below,

$$
\dot{\varepsilon}_{e q} t_{r}^{c_{1}}=c_{2} .
$$

The equation has been reported to be applicable to wide range of materials, so that rupture lifetimes obtained by Eq. (8) are reasonable to apply in this study. $c_{1}$ is the material constant making a slope of the equivalent strain rate - rupture lifetime relationship and usually takes around the value of 1 . The value is assumed to be 1 in this study. $c_{2}$ is the material constant corresponding with a creep ductility of material and varies with environmental temperature, material, applied stress etc. but this study assumes that the value of $c_{2}$ takes $40 \%$ in the following case study.

The model prosed here assumes that the creep rupture lifetimes are inversely proportional to von Mises strain rates as Eq. (8) indicates. Von Mises strains linearly accumulate with time and their strain rates are related by Norton's law with von Mises stress as Eq. (7) tells. Principal strain rates in the three directions can be calculated by Eq. (5) and (6). The rupture elongation is assumed to be $40 \%$ on von Mises bases regardless the length of rupture lifetime of materials. Rupture elongation will be smaller as rupture lifetime goes longer for conventional heat resistant steels but this paper assumes rupture elongation being constant.

\subsection{Case study of creep damage evaluation for biaxially damaged components}

Based on the multiaxial creep damage model described in the previous article, typical cases of $\lambda=0,0.5$ and 1.0 are discussed as a case study in the followings. Accumulations of principal creep strains and von Mises strain under a von Mises stress condition are depicted in Fig. 2 for three principal strain ratios. Rupture lifetimes of the three cases are set to be 
1000 hours from Eq. (8). In the uniaxial stress case shown in Fig.2 (a), von Mises strain gives the same strain rate as the $\mathrm{x}$-directional strain rate while the $\mathrm{y}$-directional and $\mathrm{z}$-directional strains have a half strain rate than the $x$-directional strain. In the $\lambda=0.5$ case shown in Fig. 2 (b), the x-directional strain has the slightly small strain rate than von Mises strain. The $y$ directional strain gives almost no strain rate and thus the z-directional strain rate becomes to almost the same rate as the $\mathrm{x}$-directional strain rate with an opposite sign. The $\mathrm{x}$-directional strain rate is the same as the $y$-directional strain rate in the $\lambda=1.0$ case and the $z$-directional strain gives a double amplitude than the $\mathrm{x}$ - and y-directional strain rates, Fig.2 (c). Von Mises strain in this case has the same strain rate as the $\mathrm{z}$-directional strain rate with an opposite sign.

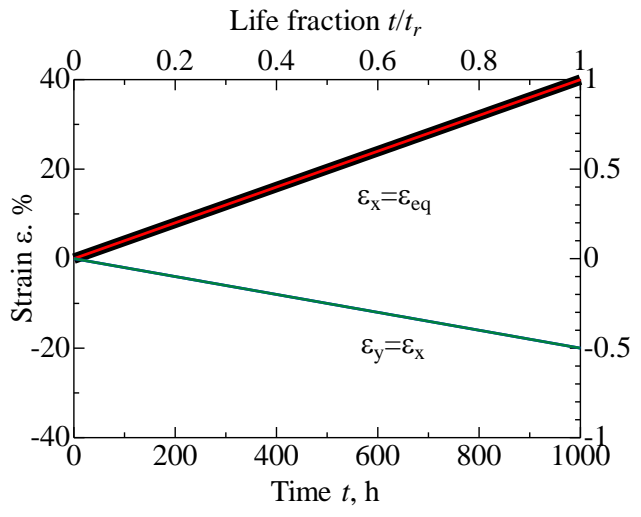

(a) $\lambda=0.0$

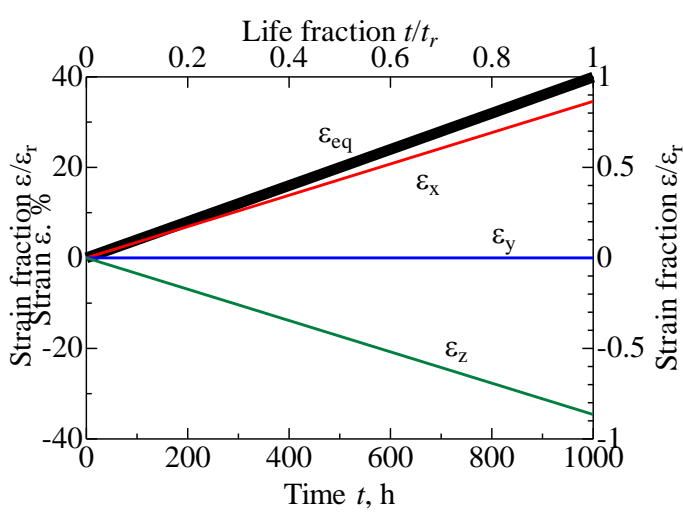

(b) $\lambda=0.5$

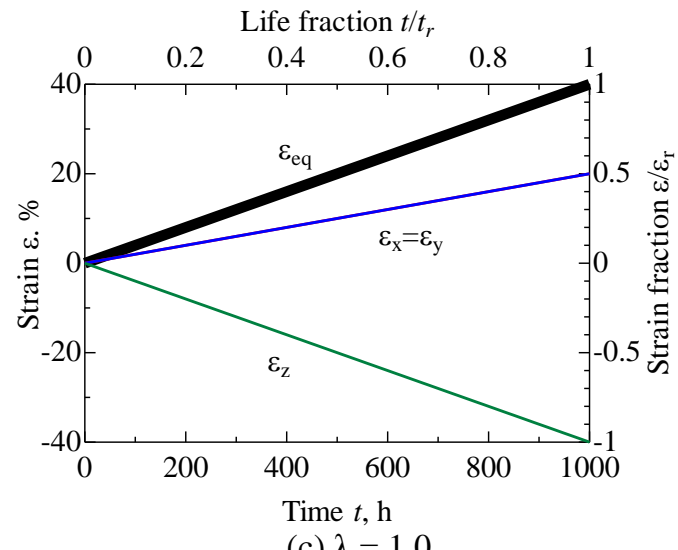

(c) $\lambda=1.0$

Fig.2. Creep strain curves.

Consider a case that an actual component underwent equi-biaxial creep damage $(\lambda=1.0)$ under a von Mises stress for 500 hours as shown in Fig.3. The von Mises strain in this case accumulates to $20 \%$ as indicated as Point A in Fig.3. The $\mathrm{x}$ - and y-directional strains at the time is a half of von Mises strain and is $10 \%$. If a miniature uniaxial creep specimen is taken from the damaged part in the $\mathrm{x}$-direction, the creep strain curve will follow the line BD giving a rupture lifetime of 750 hours. This is the unconservative estimate compared with the ongoing lifetime of the line AC under the biaxial loading. The ongoing rupture lifetime is 500 hours. This case study clearly demonstrates that the damage evaluation using a unidirectional miniature specimen in a some cases gives unconservative estimate for multiaxially creep damaged components. 


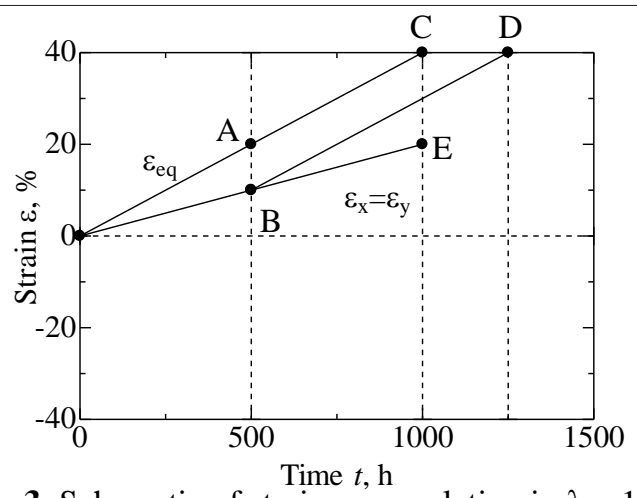

Fig. 3. Schematic of strain accumulating in $\lambda=1.0$ test.

\section{Experimental}

\subsection{Experimental procedure}

Test material used in this study is a Mod.9Cr-1Mo steel, and its chemical composition is tabulated in Table 1. This study uses cruciform and miniature creep specimens shown in Fig. 4 (a) and (b), respectively. The cruciform specimen is used for equi-biaxial tension creep tests. This specimen has a parallel part of $32 \mathrm{~mm}$ square and a gage part of $16 \mathrm{~mm}$ square. Uniform stress and strain distribution along $16 \mathrm{~mm}$ square gage part was confirmed by a finite element analysis. The miniature creep specimen machined from the gage part of the cruciform specimen has a $2 \mathrm{~mm}$ diameter and a $12 \mathrm{~mm}$ gage length.

Table 1. Chemical compositions, Mod.9Cr-1Mo steel (wt, \%).

\begin{tabular}{c|c|c|c|c|c|c|c|c|c|c|c}
\hline $\mathrm{C}$ & $\mathrm{Si}$ & $\mathrm{Mn}$ & $\mathrm{P}$ & $\mathrm{S}$ & $\mathrm{Cr}$ & $\mathrm{Ni}$ & $\mathrm{Mo}$ & $\mathrm{V}$ & $\mathrm{Nb}$ & $\mathrm{N}$ & $\mathrm{Fe}$ \\
\hline 0.1 & 0.3 & 0.4 & 0 & 0 & 8.4 & 0.2 & 0.9 & 0.20 & 0.1 & 0 & $\mathrm{Bal}$ \\
\hline
\end{tabular}

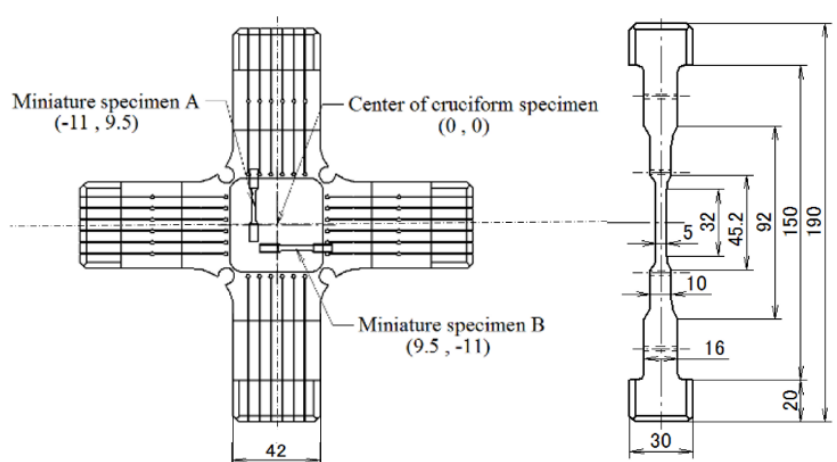

(a) Cruciform specimen

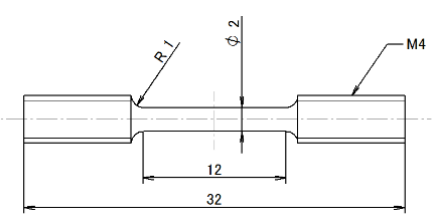

(b) Miniature specimen.

Fig. 4. Shape and dimensions of specimens tested ( $\mathrm{mm})$.

Biaxial tension creep tests were performed by a biaxial tensile creep test machine for cruciform specimens developed in-house [6] of which the schematic is illustrated in Fig. 5 (a). The test machine has four pull rods and can perform biaxial creep tests in the principal stress ratio range of $0 \leq \lambda \leq 1$. The maximum test load capable to apply is $98 \mathrm{kN}$ and the maximum test temperature of the machine is $973 \mathrm{~K}$. Creep rupture lifetimes of the miniature specimen are obtained by a miniature creep test machine shown in Fig.5 (b). Maximum 
loading capacity and maximum test temperature of the miniature machine are $1 \mathrm{kN}$ and 1073 $\mathrm{K}$, respectively. The miniature specimen was set in a superalloy tube and Ar gas was flowed in the tube to supress the oxidation of the specimen.

Biaxial and uniaxial creep rupture lifetimes were obtained using the cruciform specimen and uniaxial bulk creep specimens of which the graphical presentation is not made here. The uniaxial bulk creep specimen has a similar shape to the cruciform specimen, but the uniaxial specimen does not have two y-directional arms to apply a load. The x-directional (Miniature B) and $y$-directional (Miniature A) miniature creep specimens were machined to obtain a residual creep lifetime from the cruciform specimen after loading for a half creep rupture lifetime at $\lambda=1$. The two directional miniature specimens have a creep damage ratio of $43.3 \%$ for their total lives as mentioned later.

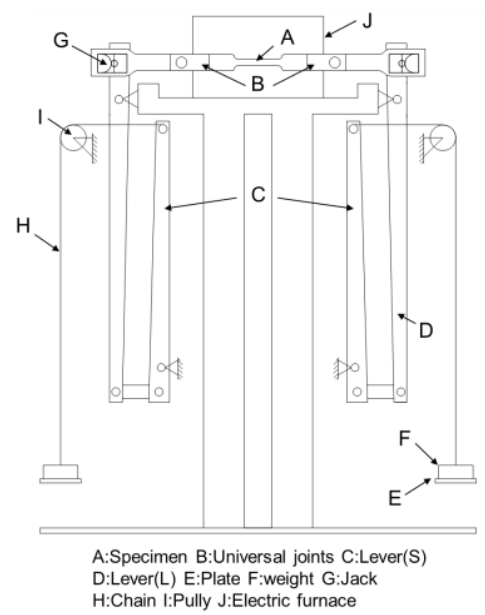

(a) Biaxial tensile creep test machine

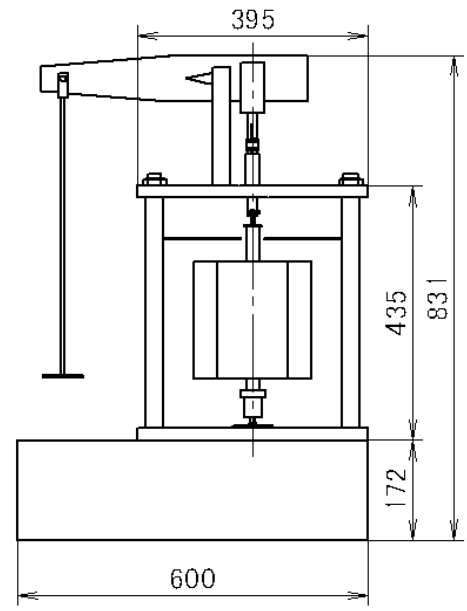

(b) Miniature creep test machine

Fig. 5. Shape and dimension of testing machine $(\mathrm{mm})$.

\section{2 Experimental results}

Fig.6 [7] correlates biaxial and uniaxial creep rupture lifetimes with von Mises equivalent stress at $873 \mathrm{~K}$ and $923 \mathrm{~K}$. Solid lines in the figure are a trend line based on the uniaxial data and all the biaxial creep rupture lifetimes are collapsed with in a factor two band indicated with dashed lines. Von Mises stress is understood to be effective to correlate the biaxial creep rupture lifetimes of the Mod.9Cr-1Mo steel at the two temperatures.

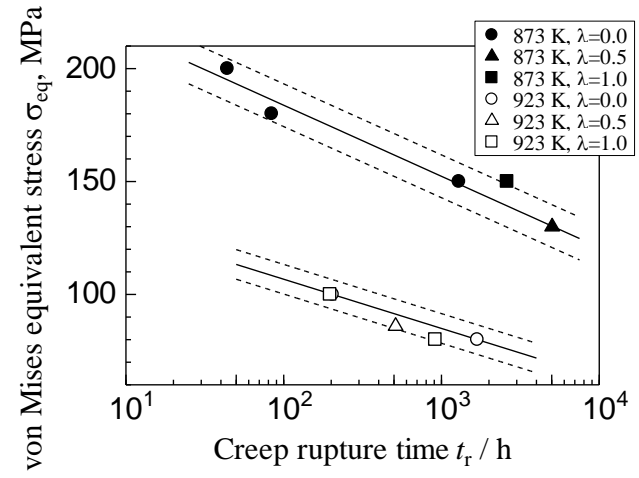

Fig. 6. Comparison of rupture life times of Mod.9Cr-1Mo steel between the uniaxial and biaxial test with von Mises equivalent stress. 
The rupture lifetime is 200 hours at $\sigma_{e q}=100 \mathrm{MPa}$ and $923 \mathrm{~K}$ as understood from Fig. 6 , and miniature specimen A and B were machined after creep loading for 86.6 hours at $\lambda=$ 1.0. The creep damage ratio at the interruption is 0.433 that is obtained by dividing 86.6 by 200. The rupture lifetime of the miniature specimens taken from this cruciform specimen was 320 hours for Miniature A and was 250 hours for Miniature B as shown in Table 2. The rupture lifetimes of the two miniature specimens lasted longer than that of no damaged specimen. From the longer creep lifetimes of the two specimens than that of no damaged specimen, all the previous studies have judged that the multiaxially stressed component had no damage, but it is damaged as is seen in Table 2. For the cases of Miniature A and B, they are damaged to 0.433 . Based on the model proposed in the previous section, the residual lives of Miniature A and B should be 150 hours, but the experimental results are longer than that. Reasons of the longer lifetimes of the miniature specimens are not clear at this moment and further model and experimental studies are necessary to account for the longer lifetimes.

Table 2. Test conditions and results.

\begin{tabular}{c|c|c|c|c|c}
\hline & $\begin{array}{c}\text { Temperature } \\
\mathrm{T}, \mathrm{K}\end{array}$ & $\begin{array}{c}\text { Load } \\
\sigma_{e q}, \mathrm{MPa}\end{array}$ & $\begin{array}{c}\text { Cruciform loading time } \\
t, \mathrm{~h}\end{array}$ & $\begin{array}{c}\text { Damage ratio } \\
\phi_{c}, \%\end{array}$ & $\begin{array}{c}\text { Rupture lifetime } \\
t_{\mathrm{r}, \mathrm{h}}\end{array}$ \\
\hline Virgin & 923 & 100 & 0 & 0 & 200 \\
\hline Miniature A & 923 & 100 & 86.6 & 43.3 & 320 \\
\hline Miniature B & 923 & 100 & 86.6 & 43.3 & 250 \\
\hline
\end{tabular}

\section{Discussion}

In the previous sections, described is the limitation of the conventional damage evaluation method of using a single miniature specimen for multiaxially damaged components by the model analysis and in experiments. In this section, a new method is discussed for evaluating multiaxial creep damage by sampling multiple directional miniature creep specimens in the two principal directions. To make that, the followings are assumed.

(i) Three principal directions and multiaxial pre-damage loading time are known.

(ii) Two miniature specimens were machined in the two principal directions of $\mathrm{x}$ and $\mathrm{y}$.

(iii) Rupture lifetimes of the $\mathrm{x}$ and $\mathrm{y}$ directionally pre-damaged miniature specimen are known.

(iv) Creep strain linearly accumulates and von Mises equivalent strain rates are proportional to a power of von Mises stress as shown in Eq. (7).

(v) Specimens fail when the accumulated creep strain reaches to $40 \%$.

Fig. 7 schematically presents the procedure of evaluating multiaxial creep damage using the two directional miniature specimens. From the two creep lifetimes of the two miniature pre-damaged specimens taken from a multiaxially damaged component, the points A and B are determined because the rupture lifetime is experimentally knows and the rupture elongation is assumed to be $40 \%$ in the above assumptions. Strain rates of the two miniature specimens are experimentally obtained so that the points $\mathrm{C}$ and $\mathrm{D}$ are reduced from the points $\mathrm{A}$ and $\mathrm{B}$ using the creep strain rates of the two miniature specimens. By connecting the points between the origin and $\mathrm{C}$ and between the origin and $\mathrm{D}$, strain rates, $\dot{\varepsilon}_{x}$ and $\dot{\varepsilon}_{y}$, during multiaxial loading are calculatable. Using the two strain rates and Eq. (4), the z-directional strain rate, $\dot{\varepsilon}_{z}$, is obtained. Finally, substituting the three principal strain rates into Eq. (3) gives von Mises equivalent strain rate under the multiaxial loading. Von Mises stress is directly obtained from von Mises strain rate by Eq. (7). Each principal stress can be determined solving a set of equations of Eq. (5) and (6). 


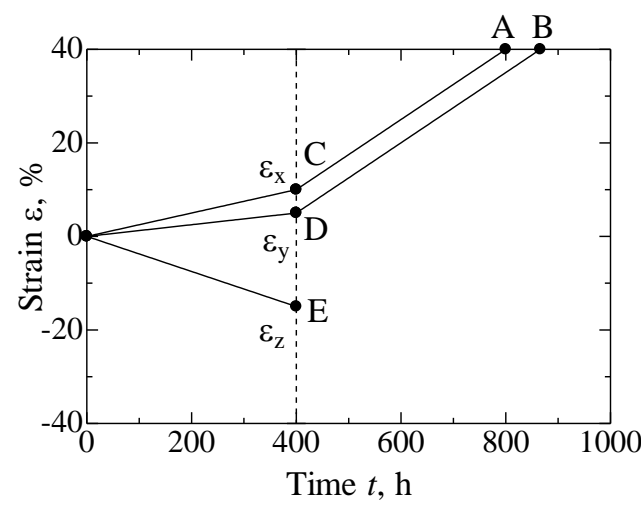

Fig. 7. Procedure of evaluating remaining life of multiaxial creep damaged component.

From the above analysis, the creep damage under a multiaxial stress state can be evaluated using von Mises stress and rupture lifetime plot like Fig.6.

\section{Conclusions}

1. The limitation of conventional miniature creep testing for evaluating multiaxial creep damage was discussed based on the creep deformation damage model. The conventional creep damage evaluation method of using a single directional miniature specimen has a possibility of giving a unconservative estimate of a multiaxially damaged component.

2. Residual lifetimes of the two directional miniature specimens taken from multiaxially damaged locations with a damage ratio of 0.433 lasted longer than that of no damaged specimen for a $9 \mathrm{Cr}-1 \mathrm{Mo}$ steel. The results demonstrate experimentally the limitation of the creep damage evaluation method of a single directional miniature specimen for a multiaxially damaged component. The trend of the rupture lifetimes of the miniature specimens agrees with that of the creep deformation damage model proposed in this paper.

3. A new damage model was proposed to estimate multiaxial creep damage of components utilizing multiple uniaxial miniature specimens.

\section{Reference}

1. K. Kimura, H. Kushima and F. Abe, "Improvement of Creep Life Prediction of High Cr Ferritic Creep Resistant Steels by Region Partitioning Method of Stress vs. Time to Rupture Diagram” Journal of Society of Materials Science, Japan, 52, 1, 57-62 (2003)

2. M. Matsubara and A. Nitta, "Creep-Fatigue Strengths of $9 \mathrm{Cr}$ steels for FBR Steam Generator" CRIEPI Research Report, 20, 1 (1988)

3. O. Kanemaru, et al., The thermal and nuclear power, 41, 326 (1990)

4. Japan Society of Materials, Fundamentals of solid mechanics, 173 (1981)

5. F.C.Monkman and N.J. Grant, "AN Empirical Relationship Between Rupture Life and Minimum Creep Rate in Creep-Rupture Tests" Proc. ASTM, 56, 593-620 (1956)

6. S. Mukai, T. Takada, M. Sakane, M. Ohnami and T. Tsurui, "Development of multiaxial creep testing machine using cruciform specimen" Journal of the Society of Material Science, Japan, 45, 5, 559-565 (1996)

7. R. Itoh, T. Hikida, F. Ogawa, T. Itoh, M. Sakane, S. Zhang, "Biaxial Tensile Creep Damage of Mod.9Cr-1Mo Steel Using Cruciform Specimen," Proc. 9th China-Jpn. Bilater. Symp. High Temp. Strength Mater., 60-66, Oct. (2016) 